\title{
I FORUM DE BIOÉTICA EM TRANSPLANTE DA AMERICA LATINA E CARIBE: 0 DOCUMENTO DE AGUASCALIENTES
}

\author{
First Latin American Forum in Transplant Bioethics: The Aguascalientes Document
}

\author{
Ashley Baquero', Josefina Alberú2, Mario Abbud-Filho³, pelos participantes do Forum
}

\begin{abstract}
RESUMO
Os questionamentos de ordem bioética relacionadas com transplantes de órgãos, colocados na segunda metade do século XX, tem motivado intensos debates e se tornaram um autêntico desafio nos âmbitos científicos, jurídicos, morais e religiosos durante todos esses anos. A questão que ainda permanece é por que razão, meio século mais tarde, ainda persiste o debate sobre a bioética dos transplantes ? O 1o Fórum de Bioética em Transplante foi concebida pela STALYC e teve por objetivo fazer uma reflexão e analisar os problemas existentes na região. $\mathrm{O}$ Forum buscaria encontrar soluções para alguns casos, tentaria estabelecer um posicionamento consensual em outros e em algumas situações se limitaria apenas a sugerir propostas. Dessa forma, a comunidade de transplantes da América Latina (AL) não permaneceria alheia aos problemas existentes e estaria desempenhando um dever que jamais poderia ser abandonado. O documento de Aguascalientes reafirma a sua identidade com os mais altos valores que definem a prática da Medicina; reafirma seu compromisso com a Dignidade, o Respeito pela Vida e de nunca deixar de exercer seu dever de ajudar aqueles que sofrem. Embora o documento de Aguascalientes admita que cada país e cada centro de transplante têm a prerrogativa de definir suas próprias práticas, ele tem a pretensão de servir como instrumento de expressão em nome dos grupos com atividades de transplantes na América Latina e no Caribe, e seu objetivo é influenciar a realização de transplantes em um ambiente de justiça e equidade.
\end{abstract}

Descritores: Ética; Transplantes; Bioética.

\footnotetext{
Instituição:

${ }^{1}$ Presidência, Sociedade de Transplantes da America Latina e Caribe, Republica Domenicana

2 Departamento de Transplantes, Instituto Nacional e Ciências, Cidade do Mexico, Mexico

${ }^{3}$ Diretoria, Centro de Transplantes, Hospital de Base/FUnFARME/FAMERP, S.J. Rio Preto, SP, Brasil

* Participantes do Forum:

COORDENADORES GERAIS DO FÓRUM: Ashley Baquero (República Dominicana), Josefina Alberú (México)

COORDENADORES DAS MESAS DE TRABALHO:

DOADOR VIVO: Eduardo Santiago Delpín (Puerto Rico), Eduardo Tanús (Argentina), Rafael ReyesAcevedo (México).

TURISMO E COMERCIO DE TRANSPLANTE: María Amalia Matamoros (Costa Rica), Roberto Tanús (Argentina)

LEGISLACÃO E ALOCAÇÃO: Mariela Salome Bacile (Argentina), Sergio Orihuela (Uruguay)

COBERTURA PARA TRANSPLANTES E PARA IMUNOSSUPRESSÃO: Mario Abbud-Filho (Brasil), Maria del Carmen Bacque (Argentina), Domingo Casadei (Argentina).

PARTICIPANTES DO FÓRUM: Alger Aquino Figueroa (México), Roberto Barriga Arroyo (Bolivia), Martha Magalis Bello Bello (República Dominicana), Milka Bengochea (Uruguay), Jorge David Cancino López (México), Guillermo Rafael Cantú Quintanilla (México), Gilberto Castañeda Hernández (México), Irene Córdova (México), Ramón Espinoza Pérez (México), José Pablo Garbanzo Corrales (Costa Rica), Carmen Gracida Juárez (México), María de Jesús Gutiérrez Navarro (México), Mariela Mautone (Uruguay), José Luis Medina Cerriteño (México), Avelino Méndez Rangel (México), Arnoldo Mondragón Padilla (México), Cruz Netza Cardoso (México), María del Carmen Rial (Argentina), Ana Rodríguez Allen (Costa Rica), María de la Cruz Ruiz Jaramillo (México), Luciano Zylbuberg (México).

Correspondência:
}

Nome: Mario Abbud Filho

Endereço: Rua Raul de Carvalho, 2.735, CEP 15020-020, São José do Rio Preto/ SP

Tel.: (17) 4009-9191

E-mail: mabbud@terra.com.br

Recebido em: 08.09.2010

\section{DOCUMENTO DE AGUASCALIENTES}

\section{EXPOSIÇÃO DE MOTIVOS}

Os avanços técnico-científicos obtidos ao longo das últimas seis décadas estabeleceram o transplante de órgãos como alternativa terapêutica para tratamento de pacientes com falência crônica de órgãos. A possibilidade de oferecer esses procedimentos para os pacientes exigiu grande generosidade e altruísmo por parte dos doadores e seus familiares.

Desde os anos 50, quando os primeiros transplantes em seres humanos foram executados, ${ }^{1-3}$ surgiu uma série de dúvidas bioéticas relacionadas à realização dos transplantes, ${ }^{4-6}$ tanto pela necessidade de estabelecer critérios a respeito da morte, quanto pelo fato de ter sido incorporado pela prática da medicina dos transplantes um componente até então inédito: o doador de órgãos.

Os questionamentos de ordem bioética relacionados com transplantes de órgãos, colocados na segunda metade do século $\mathrm{XX}$, têm motivado intensos debates, além de haver se tornado um autêntico desafio nos âmbitos científicos, jurídicos, morais e religiosos durante todos esses anos. ${ }^{4-11}$

É preciso reconhecer que esses debates gradativamente levaram ao estabelecimento de uma ordem internacional para a prática de transplantes. Os critérios de morte encefálica foram claramente definidos, ${ }^{12-18}$ e durante as últimas quatro décadas foram aceitos de forma quase universal. ${ }^{19-22}$ Da mesma forma, foi também possível definir regras e condições ideais para a realização dos transplantes. 
A questão que ainda permanece é: por que razão, meio século mais tarde, ainda persiste o debate sobre a bioética dos transplantes ?

Vários argumentos podem explicar essa situação e os mais importantes são aqueles que inspiraram a realização deste $1^{\circ}$ Fórum Latino-Americano de Bioética em Transplante:

1. Os transplantes de órgãos consolidaram-se como procedimento terapêutico para uma grande quantidade de doenças consideradas terminais. Isso criou a necessidade de assegurar que os pacientes tenham acesso oportuno e justo à atenção médica e também aos tratamentos médicos com custo muito elevados.

2. Os órgãos para transplantes obtidos de pessoas falecidas ainda constituem um recurso escasso. Devido ao número crescente de pacientes que necessitam de um transplante, é absolutamente indispensável garantir que existam condições de eqüidade no acesso a esse recurso.

3. Transplantes com doadores vivos também não estão isentos de discussão, pois, em face da crescente demanda por órgãos para transplantes, há sempre a possibilidade dos centros transplantadores serem mais permissivos na aceitação de doadores e com isso comprometerem a segurança deles. Além disso, a pressão representada pela elevada demanda de órgãos pode favorecer práticas de comércio em transplantes.

4. Os países exigem sistemas legislativos que assegurem condições ideais para a doação e transplante de órgãos humanos.

A medicina dos transplantes é praticada com grande dignidade e profissionalismo em todo o mundo. Ela é uma ramificação da ciência médica contemporânea, sua contribuição científica tem sido vasta e generosa e milhares de seres humanos tem sido por ela beneficiados. Apesar disso, é necessário reconhecer que existem alguns pontos da prática de transplante que ainda merecem atenção cuidadosa.

Recentemente, a $63^{\text {a }}$ Assembléia Mundial de Saúde, por unanimidade, concordou com os Princípios da Organização Mundial de Saúde (OMS) sobre transplante de células, tecidos e órgãos, aprovando várias medidas para otimizar a segurança e eficácia dos transplantes. O documento da OMS “condena o tráfico de órgãos e turismo de transplantes e estimula os profissionais de saúde a notificarem essas práticas às autoridades competentes e, dessa forma, melhorar a segurança e eficiência na doação e transplante, promovendo as melhores práticas internacionais". ${ }^{23}$

No entanto, a desproporção existente em todo o mundo entre a demanda crescente e a oferta limitada de transplante de órgãos tem propiciado práticas indesejáveis“, como o tráfico de seres humanos para serem usados como fontes de órgãos e turistaspacientes de países ricos que viajam ao exterior para comprar órgãos de pessoas mais pobres, conforme apresentado e discutido no documento denominado Declaração de Istanbul. ${ }^{24}$ Esse documento, que adotou como base os princípios da Declaração Universal dos Direitos Humanos, ${ }^{25}$ ressaltou a necessidade imperiosa de uma colaboração internacional, visando obter consenso mundial com relação à otimização das práticas de doação e transplante. Sua elaboração foi fruto do trabalho de mais de 150 representantes de organizações médicas e científicas, funcionários de governo, cientistas sociais e eticistas de todo o mundo. Na Declaração de
Istambul foi enfatizado que "o legado dos transplantes deve ser a celebração da doação de saúde de uma pessoa para outra e não de indivíduos empobrecidos vítimas do tráfico de órgãos e do turismo de transplante". ${ }^{24}$ Deve-se acrescentar que o assunto em debate tem uma longa história e tradição e o seu principal objetivo é a proteção ao doador e à prática do transplante, realizada sempre nas melhores condições, com programas, pessoal e corpo docente devidamente instruídos e certificados. ${ }^{26-32}$

Os esforços para divulgar a Declaração de Istambul, desenvolvidos pelas autoridades sanitárias e outras organizações mundiais envolvidas com transplantes, têm sido meritórios e seu principal objetivo é ordenar e padronizar, em todo o mundo, as melhores práticas em matéria de doação e transplante de órgãos. Muitos países adotaram os princípios contidos na Declaração de Istambul e, após adoção de seus preceitos, observaram uma influência positiva nos programas de transplantes.

A América Latina e o Caribe constituem uma região multicultural de grande diversidade e contrastes, com pontos coincidentes com relação à prática do transplante, embora com um desenvolvimento desigual em educação e saúde. Entretanto, estudos dos últimos dez anos mostraram que em todos países da região, sem exceção, os transplantes estão crescendo de forma progressiva. Os resultados do Registro de Transplantes da América Latina, documento da Sociedade de Transplante da América Latina e Caribe (STALYC), mostram que em seis anos o número de órgãos obtidos de doadores falecidos aumentou 3,8 por milhão de população (pmp), com a perspectiva de, em 10 anos, alcançar a média de 20 pmp, com taxa de crescimento anual de $1-1,5 \mathrm{ppm}^{33}$

A mesma tendência de crescimento foi observada nos transplantes de diferentes tipos de órgãos durante o mesmo período de análise (dez anos). Enquanto o crescimento anual do transplante renal aumentou de $7 \%$ para 15,7 pmp, os transplantes de fígado $(3,4$ pmp) e de coração aumentaram $11 \%$ e 5,8\% respectivamente. ${ }^{33}$

Essa potencialidade da região cria um cenário particularmente interessante, pois permite ao Fórum investigar os progressos obtidos e ainda possibilita o estudo dos pontos fracos do sistema, produtos da realidade socioeconômica e das políticas de saúde existentes em cada país. Esse fato também ressalta a necessidade da implantação de estratégias que garantam a transparência, acessibilidade e qualidade na atividade de transplantes na América Latina e no Caribe.

A idéia de realizar o 1o Fórum de Bioética em Transplante foi concebida pela STALYC e teve por objetivo fazer uma reflexão e analisar os problemas existentes na região. O Fórum buscaria encontrar soluções para alguns casos, tentaria estabelecer um posicionamento consensual em outros e em algumas situações se limitaria apenas a sugerir propostas. Dessa forma, a comunidade de transplantes da América Latina (AL) não permaneceria alheia aos problemas existentes e estaria desempenhando um dever que jamais poderia ser abandonado .

O Fórum não se limitou a tratar exclusivamente dos aspectos relacionados com a bioética do transplante, que foram sua prioridade, mas buscou também avaliar as bases legais usadas nos países da 
AL para estabelecer uma legislação de transplante e de alocação de orgãos provenientes de doadores falecidos, identificando suas virtudes e propondo soluções para suas deficiências, de modo a aplicar corretamente os princípios éticos fundamentais. Da mesma forma, tentou conhecer os métodos usados pelas diversas autoridades de saúde dos países para proporcionar uma cobertura médica universal e permanente, requerida pelos pacientes que recebem transplantes, incluindo a terapia imunossupressora e a qualidade dos medicamentos oferecidos, além do compromisso, no curto e longo prazo, de seguimento dos doadores vivos.

Com o propósito de produzir um documento suficientemente abrangente e útil, médicos envolvidos com a prática de transplantes e especialistas em bioética da América Latina e do Caribe foram convidados a participar do Fórum. O grupo teria que estudar em detalhes as práticas atualmente vigentes em nossos países, detectar deficiências e propor soluções que, no momento adequado, seriam discutidas por grupos de trabalho no decurso do I Fórum, realizado em Aguascalientes, México, de 2 a 4 de Setembro de 2010. Durante o evento, os coordenadores de cada uma das quatro mesas de trabalho e o grupo de participantes analisaram os pareceres e as propostas acordadas. Para conclusão das discussões, os participantes do Fórum reuniram-se em sessão plenária e os resultados e propostas para cada tema foram apresentados para discussão coletiva. Ao final, foi elaborado um esboço de documento, enviado posteriormente para todos os participantes para reavaliação e comentários finais, segundo os princípios de reflexão, critérios de análise e diretrizes de ação.

Por razões de logística e organização, quatro temas foram escolhidos para serem discutidos durante o I Fórum sobre Bioética de Transplantes:

I. Doador vivo

II. Turismo para Transplante e Comércio de orgãos

III. O papel do governo na Alocação de orgãos, Legislação e Cobertura para Transplantes

IV. Acesso e Qualidade da Imunossupressão

\section{DOADOR VIVO}

Embora a avaliação de um potencial doador deva ser circunscrita apenas aos aspectos biopsicológicos, é difícil não considerar todas as outras circunstâncias que poderiam influenciar na decisão final para doar.

No caso do doador de rim, nem o ato cirúrgico, nem a futura situação de uninefrectomizado estão isentas de riscos. Na verdade, algumas pessoas consideradas boas candidatas para a doação renal, de acordo com os critérios atuais, podem estar em situação limite para a doação em relação à idade, peso ou pressão arterial, e para essas pessoas haveria riscos em curto ou longo prazo. Situações semelhantes podem surgir em doadores vivos de outros órgãos como o fígado, por exemplo.

Portanto, considera-se responsabilidade de cada programa de transplante estabelecer um sistema que garanta uma avaliação criteriosa do doador, minimizando os riscos adicionais inerentes à operação. Idealmente, essa tarefa deve ser realizada por um grupo de profissionais independentes e experientes em transplante para avaliar o doador em suas diversas fases: a pré-cirúrgica, a da cirurgia, a dos cuidados pós-operatórios imediatos e o acompanhamento em longo prazo para monitoramento da saúde do doador. Um comitê interdisciplinar de transplante também é indispensável para ajudar nessa decisão. O princípio de não prejudicar ou de não-maleficência ("do not harm") deve ser assumido e sempre ser considerado acima dos outros princípios da bioética, visando proteger o doador de riscos adicionais, mesmo quando esse doador pretenda exercer sua autonomia e insistir na doação.

\section{A. DEFINIÇÕES}

1. Doador vivo de parente consangüíneo: doador geneticamente relacionado com o receptor do primeiro ao quarto grau de consangüinidade (pai, mãe, irmãos, avós, tios ou primosirmãos).

2. Doador vivo não-aparentado:

A. doador emocionalmente relacionado ao receptor: são doadores que não têm parentesco ou relação genética mas que têm uma forte ligação emocional com o receptor, de uma forma perceptível e óbvia e que possa ser comprovada. Nessa categoria incluem-se cônjuges, concubinas, padrastos, madrastas e filhos adotivos.

B. doador não-relacionado: aqueles que não têm nenhum tipo de relação com o receptor e podem ser:

- doador altruísta: a pessoa que se oferece para doar um órgão para qualquer outra pessoa enferma, mesmo sendo pessoa desconhecida, preocupada com o bem-estar dos outros e por razões puramente humanitárias.

- doador pareado: quando um dos membros de uma dupla (par/casal) é utilizado como doador para outro indivíduo membro de outro par, de forma cruzada, em virtude da existência de incompatibilidade ABO, hipersensibilização, doença renal hereditária ou ausência de outro doador disponível entre os membros dos pares.

- doador pago: inclui a pessoa que vende um de seus órgãos por meio "regulamentado" ou ilegal.

\section{B. RECOMENDAÇÕES PARA ACEITAÇÃO DO DOADOR VIVO}

Doador vivo aparentado por consangüinidade: o doador de primeiro, segundo, terceiro ou quarto graus é aceitável.

Doador pareado: são apenas aceitáveis entre pares com doadores vivos, relacionados por consangüinidade ou emocionalmente. Todos os pares devem ser avaliados por comissões hospitalares especializadas e devem obter autorização das autoridades judiciais e de saúde de seus países.

Doador vivo não relacionado, seja por consangüinidade ou emocionalmente, não é aceitável exceto os incluídos nas seguintes categorias: 
Doador altruísta: poderá ser aceito quando não houver doação dirigida. Recomendamos que todos os casos sejam cuidadosamente avaliados por comissões de peritos, autorizados pelas comissões de ética e pelas autoridades de saúde e judiciais.

Emocionalmente relacionados: Inclui marido ou esposa, concubinas, padrastos e madrastas, filhos e filhas adotivos; são aceitáveis quando legalmente comprovados e após aprovação pelos comitês de ética e autoridades judiciais.

Doador pago: Esse tipo de doador não deve ser aceito em nenhuma circunstância.

\section{PRINCÍPIOS BIOÉTICOS GERAIS RECOMENDADOS:}

Os princípios fundamentais da bioética que devem ser contemplados são: dignidade e integridade, beneficência e não-maleficência, precaução e/ou vulnerabilidade, autonomia , responsabilidade e justiça distributiva local.

Bioética como ciência e arte está em contínua evolução. Consequentemente, novos princípios foram desenvolvidos para esclarecer os conflitos colocados pelo progresso das Ciências da Vida e outros previamente estabelecidos foram retomados. Se os primeiros princípios da beneficência, não- maleficência, autonomia e justiça foram desenvolvidos no contexto anglo-saxão, a globalização da bioética requer novas contribuições que têm sido feitas no campo do conhecimento humano.

Por Dignidade Humana entendemos que a pessoa vale por si só e não tem preço, não pode ser objeto de lucro. Beneficência significa agir no melhor interesse do doador e receptor. Integridade e Não-Maleficência são o direito do indivíduo preservar sua unidade funcional e a Precaução e/ou Vulnerabilidade é a ameaça para a fragilidade de uma totalidade em perigo biológico, psicológico e cultural.

Autonomia: a palavra é derivada do grego "autos" (Próprio) e "nomos" (Regra), autoridade ou lei. Ser autônomo significa assumir o direito de ter opiniões próprias, de escolher e tomar decisões baseadas em seus valores de crenças pessoais. Portanto, é fundamental respeitar os pontos de vista e os direitos das pessoas, desde que suas idéias e ações não impliquem em danos para os outros ou para si próprios. ${ }^{34,35}$

O princípio da Responsabilidade é definido como a obrigação de todos aqueles que têm acesso à ciência e à tecnologia serem conscientes de suas próprias ações, agirem em conformidade e com respeito pela vida humana e para preservação da mesma. ${ }^{36}$

Justiça Distributiva e Local: O termo justiça distributiva referese à fragmentação adequada dos bens e/ou dos encargos de uma sociedade para compensar as desigualdades em que vive a sociedade. Dessa forma, os recursos, os impostos e as oportunidades podem ser distribuídos de forma equitativa. O princípio da Justiça em Bioética inclui o acesso aos recursos e a promoção da saúde, com capacidade de responder às necessidades da comunidade e proteção do Estado. Para explicar a justiça distributiva nos serviços de saúde utilizamos os termos de mérito, equidade e participação no que se tem direito. Diz-se que a situação é justa quando a pessoa recebe todos os benefícios que tem direito. A injustiça ocorre quando um indivíduo é privado da sua devida atenção por necessidade ou condição social.

A justiça distributiva visa ainda supervisionar os métodos utilizados na distribuição adequada das terapias substitutivas, tais como o transplante, e evitar discriminação. ${ }^{37-39}$

O documento de Aguascalientes assume uma estrutura hierárquica para os conceitos de Solidariedade e Subsídios.

Solidariedade: se todo ser humano tem o direito de encontrar o que precisa para seu crescimento e desenvolvimento, a solidariedade consiste em fazer nossas, as necessidades daqueles que não têm esses recursos, para que possam obter os meios de subsistência e os instrumentos para seu progresso pessoal. Subsidiar: Em uma realidade social com notáveis diferenças de oportunidades, esse princípio pretende estabelecer que, quem mais sabe, tem e pode, atenda aos necessitados. Isso não deve limitar a iniciativa ou a responsabilidade das pessoas ou dos grupos sociais que, ao contrário, devem valorizar, promover e aumentar esses subsidios. Além disso, é fundamental estabelecer uma responsabilidade conjunta com a equipe de tratamento e os pares de doador-receptor e seu ambiente social. Essa responsabilidade conjunta não isenta o Estado de sua responsabilidade. Assim, é imprescindível salientar o seguinte:

Consentimento Informado: No documento de Aguascalientes reiteramos a obrigatoriedade da utilização do Termo de Consentimento Informado, com todos os seus componentes, para salvaguardar a autonomia do doador e do paciente em todo o procedimento de transplante. Esses componentes são: Voluntarismo: deve garantir que as pessoas escolham livremente submeter-se a um processo, tratamento médico ou estudo clínico, sem que sua autorização tenha sido obtida por meio de persuasão, coerção ou manipulação. O Direito à Informação: deve ser de fácil entendimento e incluir o objetivo da análise médica, tratamento ou procedimento. Os benefícios e os riscos a curto, médio e longo prazo do procedimento ou tratamento médico devem ser claramente explicados às pessoas e, da mesma forma, as alternativas terapêuticas.

Compreensão: O nível de compreensão do paciente deve ser avaliado por pessoas diferentes, além do médico. Essas informações podem ser obtidas através do psicólogo, assistente social ou pessoal de enfermagem que entendem e conhecem em detalhes o procedimento que é oferecido ao paciente ou ao doador de órgãos. A informação deve ser dada ao paciente na sua própria língua ou dialeto da região. Um tradutor ou intérprete deve estar presente durante todo o tempo que o paciente estiver recebendo informações. Caso a autorização por escrito não seja na língua materna de quem assina concedendo sua autorização, o documento deve conter a assinatura do tradutor e de pelo menos dois funcionários da instituição. Ainda, deve ser atestado que o conteúdo do consentimento escrito é o mesmo que se encontra no documento traduzido. É necessário ter em conta o nível de escolaridade e o desenvolvimento social do doador para garantir que o mesmo conseguiu entender completamente o que foi explicado verbalmente e por escrito.

As Sociedades de cada país devem utilizar estratégias para que, 
juntamente com seus legisladores, façam leis nacionais com base nas leis internacionais, com a finalidade de obter ou manter os bons resultados e de proteger os direitos dos receptores e doadores.

\section{TURISMO PARA TRANSPLANTE E COMÉRCIO DE ORGÃOS}

Associado ao sucesso dos transplantes de órgãos veio também uma facilitação na obtenção de doadores vivos não-aparentados e a utilização de órgãos de prisioneiros condenados à morte na China, provocando críticas de todo o mundo. Preocupada com a situação denunciada, a Sociedade de Transplante da América - Latina e Caribe considerou ser necessário manifestar-se sobre o turismo para transplantes e venda de órgãos.

As práticas não éticas em transplantes fomentam a desigualdade e a exploração das pessoas e são conhecidas. ${ }^{40}$ Essas práticas antiéticas são baseadas em argumentos falsos, como o "benefício" e a "oportunidade" que uma pessoa pode obter para melhorar sua condição econômica. Da mesma forma, utilizam a "autonomia" para justificar o direito que as pessoas têm de vender os seus órgãos. No entanto, esse é apenas um disfarce para um "negócio ilícito", onde não são as pessoas necessitadas de dinheiro que se beneficiam da venda de seus órgãos, mas sim os intermediários que enriquecem com esse tipo de venda. Está claramente definido que os pobres, por serem mais vulneráveis, submetem-se ao risco de participar desse tipo de procedimento. A situação de polarização na distribuição da riqueza nos países de nossa região, a elevada taxa de pobreza e o baixo nível de escolaridade exigem que a América Latina tome medidas necessárias para proteger sua população vulnerável dessa nova forma de exploração humana, que é o tráfico e o comércio de órgãos para transplantes.

Subscrevemos o documento de Aguascalientes com as seguintes definições provenientes da Declaração de Istanbul: ${ }^{24}$

Tráfico de Órgãos é a obtenção, transporte, transferência, alojamento ou o acolhimento de pessoas vivas ou falecidas ou de seus órgãos por meio de ameaça ou uso da força, ou outras formas de coação, rapto, fraude, engano, abuso de poder ou pela vulnerabilidade, tanto por aquele que oferece como por quem recebe o órgão, incluindo pagamentos a terceiros ou benefícios para obter a transferência ou o controle sobre um doador em potencial, para fins de exploração através da remoção de órgãos para transplante.Comércio de órgãos é quando um órgão é tratado como um bem econômico que pode ser comprado, vendido ou usado como mercadoria. Turismo para transplante é o movimento de doadores de órgãos, receptores ou profissionais relacionados com o transplante que atravessam as fronteiras jurisdicionais para efeitos de realização de transplantes. Viagens para transplante tornam-se Turismo para transplante quando envolvem tráfico e/ ou o comércio de órgãos ou de outros recursos, como profissionais ou centros de transplante que realizam transplantes em pacientes estrangeiros, comprometendo a capacidade do país de fornecer serviços de transplante adequados para a sua própria população.

$\mathrm{O}$ documento de Aguascalientes é enfaticamente contra qualquer idéia ou mecanismo que favoreça o comércio de órgãos e tecidos por parte de indivíduos ou dos Estados. Ele se opõe a qualquer mecanismo que disfarce o comércio de órgãos ou ao funcionamento de qualquer tipo de organização que aceite órgãos como artigos comercializáveis, como por exemplo, o mercado regulamentado, a venda livre de órgãos, ou o pagamento para doadores de quantias superiores àquelas decorrentes das despesas com estudos de avaliação, procedimento cirúrgico, acompanhamento e complicações após o ato de doar um órgão.

\section{OPAPELDOESTADO NA LEGISLAÇÃO, DISTRIBUIÇÃO E COBERTURA PARA TRANSPLANTE}

Presumindo-se que nossos Estados são responsáveis pelo bem-estar dos cidadãos e devem promover o bem estar comum, vale ressaltar o papel do governo no financiamento, manutenção, fornecimento, controle e vigilância das atividades relacionadas com o transplante de órgãos, tecidos e células de origem humana.

A crescente demanda por doação de material biológico de origem humana para atender a situação de milhares dos nossos cidadãos exige de nossos países o desenvolvimento ordenado dos sistemas de doação e transplante e de políticas específicas enquadradas em um contexto ético e legal, contemplando o bem comum e o acesso universal.

Em cada um dos nossos países, em maior ou menor grau, existe um forte e crescente desequilíbrio entre oferta e demanda de transplantes de órgãos, uma fragmentação da atenção e um acesso parcial ou restrito ao transplante como uma alternativa terapêutica para grandes setores da população da América Latina e do Caribe.

Embora em muitos de nossos países ainda exista uma ampla margem para crescimento na taxa de doadores falecidos, outras alternativas usadas internacionalmente estão sendo analisadas e, se julgadas apropriadas, necessitarão de um rigoroso controle ético-legal e de cidadania.

Perante essa situação, a única atitude aceitável é a do compromisso dos diferentes segmentos de nossa sociedade, especialmente daqueles que têm grandes responsabilidades políticas, ético-legais, sanitárias, técnicas e econômicas. Nesse novo contexto, um papel muito especial corresponde à sociedade civil, com uma atitude mais ativa e organizada na defesa dos seus direitos.

A decisão política de incrementar essa política com objetivos claros, garantindo o direito ao transplante, aumento do número e melhoria nos resultados de transplantes e redução das listas de espera, deverá ser realizada com a elaboração de programas de doação e transplante, visando estabelecer com eqüidade, cobertura e atenção integradas. É necessário deixar claro que a correta aplicação dessas medidas exige que os Estados garantam a cobertura universal dos serviços de saúde a todos os cidadãos que necessitem de transplante. Essas medidas devem considerar as particularidades organizacionais de cada Estado, sempre obedecendo às diretrizes éticas.

Nos países onde não há nenhuma doação e atividade de transplante em vigor, as autoridades devem maximizar esforços para desenvolver sistemas que atendam às necessidades de sua população visando a auto-suficiência.

Em todos os casos, a população deve encontrar disponíveis todas as informações sobre o acesso aos programas de transplante vigentes, aos resultados de sobrevida dos pacientes e enxertos dos centros que realizam transplantes, disponibilidade, cobertura níveis e critérios de 
alocação. $\mathrm{O}$ acesso à informação por parte dos vários intervenientes, incluindo os pacientes, permite a garantia de transparência na alocação e obriga a apresentação dos seus resultados.

\section{ACESSO E QUALIDADE DOS IMUNOSSUPRESSORES}

O objetivo é garantir a saúde dos pacientes com o uso de medicamentos de qualidade e eficácia comprovados, por meio de um processo definido e aprovado por uma instituição científicoacadêmica, ${ }^{41}$ isso não implica na aprovação ou desaprovação do uso de medicamentos genéricos, mas requer o cumprimento das condições mencionadas.

A cobertura para os transplantes deve incluir a implementação de estratégias de saúde que garantam o acesso, qualidade, equidade, transparência e eficácia na atenção ao paciente; permitir o rápido registro na lista de espera, permanecer na lista de espera por períodos breves e oferecer a possibilidade do paciente receber um transplante com perspectiva de reinserção plena na sociedade.

A atividade de transplante implica em um compromisso ético do profissional, não só com o paciente, mas com a comunidade, com o seu espírito de solidariedade que torna possível a doação de um órgão comum e escasso, e também envolve a responsabilidade com o paciente que permanece na lista de espera.

O Estado deve olhar para a manutenção do vínculo médicopaciente no âmbito ético, que pressupõe o respeito pela dignidade e autonomia do indivíduo. Qualquer alteração ou disposição que altere o equilíbrio ameaça o bem-estar psicofísico do paciente.

A problemática sobre a incorporação de medicamentos imunossupressores genéricos no mercado é de grande pertinência. Esse é um debate universal e até agora não há informação bibliográfica suficiente sobre a segurança terapêutica dos imunossupressores genéricos e muito menos sobre os resultados do intercâmbio entre eles.

A fiscalização da qualidade do medicamento imunossupressor que o paciente recebe é obrigação ética do médico de transplante. Portanto, deve-se garantir o respeito pela prescrição feita e também devem ser dadas ao paciente todas as informações para ele poder exercer sua autonomia e tomar uma decisão livre. Qualquer mudança no tratamento imunossupressor deve ser autorizada pelo paciente, por meio da assinatura do consentimento informado, legalmente previsto. Da mesma forma, deve haver um acordo sobre quem terá a responsabilidade legal pelas conseqüências devido à mudança na medicação.

Os imunossupressores formam uma categoria especial de medicamentos e apresentam características especiais que os tornam diferentes de outros grupos terapêuticos; ${ }^{42}$ são medicamentos com alto risco para a saúde, pois apresentam uma janela terapêutica reduzida e têm alto nível de variabilidade inter-populacional e intraindividual. Assim, erros na dosagem, mesmo quando pequenos podem resultar em: 1) falta de eficácia com perda do transplante, 2) imunossupressão excessiva acompanhada por infecções, ou 3) efeitos indesejáveis graves devido à toxicidade peculiar do medicamento. Isso resulta na grande variação da biodisponibilidade dos medicamentos imunossupressores em pacientes transplantados, significativamente maior do que em voluntários saudáveis.
Consequentemente, os resultados de estudos sobre a bioequivalência farmacocinética realizados em voluntários saudáveis não podem ser extrapolados diretamente para a população, altamente heterogênea, dos pacientes transplantados. Portanto, é necessária a realização de estudos clínicos sobre a eficácia e segurança dos imunossupressores genéricos que poderão fornecer provas de equivalência, ou pelo menos de não-inferioridade, com relação aos imunossupressores com patentes certificadas. ${ }^{43}$

Consideramos que há necessidade das autoridades de saúde, por meio das entidades dedicadas à regulamentação de medicamentos, submeterem os medicamentos imunossupressores genéricos para estudos de monitoração das concentrações terapêutica no soro, plasma ou no sangue de pacientes transplantados, a fim de avaliarem a variabilidade intra- e inter-individual das diferentes formulações disponíveis. Além disso, estudos de farmacovigilância intensiva deverão ser iniciados visando reconhecer as variáveis que possam interferir na biodisponibilidade dos novos fármacos. ${ }^{43}$

Também é necessário implantar e ajustar um sistema para registrar informações e torná-lo disponível para que todos os médicos possam fornecer dados sobre os efeitos adversos, e que isso seja facilmente encontrado em páginas da web de sociedades científicas, em conjunto com as autoridades reguladoras, para facilitar o cumprimento da farmacovigilância. Recomenda-se às sociedades científicas de cada país gerar um fluxo de informações sobre farmacovigilância para ser distribuído nos hospitais de transplante e nas unidades de saúde onde é feito o acompanhamento de pacientes com baixo risco imunológico.

O intercâmbio entre imunossupressores inovadores e imunossupressores genéricos não é recomendável se todo o processo de verificação do efeito clínico do genérico não tiver sido realizado. Pacientes pediátricos, adultos idosos e pacientes de alto risco imunológico representam grupos vulneráveis e não devem ser incluídos em qualquer protocolo de intercâmbio de drogas. ${ }^{43}$

$\mathrm{O}$ argumento de aquisição de imunossupressores genéricos a preços mais baixos não é válido no âmbito dos princípios da bioética que devem ser cumpridos na atenção do paciente, tais como beneficência e não-maleficência. Além disso, deve ser levado em consideração que a Farmacoeconomia não inclui apenas os custos de aquisição, mas também os custos associados com a falta de eficácia e segurança de um medicamento. Se o uso de genéricos resultar em maior taxa de rejeição do transplante, a economia gerada pelo baixo preço do medicamento será superada pelos custos associados a uma falha terapêutica. Portanto, o uso de um imunossupressor genérico de má qualidade poderá gerar despesas adicionais. Em contraste, um imunossupressor genérico que apresenta eficácia e segurança, comparável com a do tipo inovador, mas com um custo menor, pode gerar uma economia significativa. Esse é o tipo de medicamento imunossupressor genérico que deve ser estimulado pelas autoridades regulatórias. ${ }^{43}$

Finalmente, consideramos que é uma oportunidade para que as autoridades de saúde definam políticas que permitam garantir a cobertura universal do tratamento imunossupressor e que, em conjunto com as entidades reguladoras, autorizem a comercialização dos novos medicamentos genéricos, quando esses medicamentos tenham assegurado um padrão de qualidade..$^{4-46}$ 


\section{RECOMENDAÇÕES EM NÍVEL DE PAÍSES E DE PROGRAMAS.}

São condições para o desenvolvimento de um sistema saudável de doação e transplante de cada país da região:

1. Contar com uma legislação específica com base em considerações bioéticas que contemple a regulamentação da doação, alocação de transplante e de seguimento.

2. Garantir o acesso universal aos serviços de saúde, incluindo o acesso ao transplante, em todos os países da região.

3. Estabelecer uma organização estatal nacional encarregada pela doação, procura, alocação e distribuição dos órgãos, e também da promoção e execução das políticas de transplantes em nível nacional.

4. Fomentar programas de doadores falecidos e utilização máxima dos recursos de cada país, a cooperação internacional, incluindo a troca de recursos médicos-clínicos, educacionais, científicos e bioéticos, além de investigação científica em imunologia, doação e transplante.

5. Dispor de uma lista nacional de espera para cada órgão ou tecido, e sistemas de alocação com critérios definidos que promovam a ordem, segurança, transparência, credibilidade e rastreabilidade no sistema.

6. Promover o estabelecimento de controles necessários nas instituições de saúde para a proteção da população vulnerável.

7. Fazer vigorar os princípios de Justiça Distributiva, Utilidade, Igualdade e Comunidade.

8. Criar/implementar sistemas de monitoração e fiscalização dos sistemas de alocação.

9. Promover a obrigatoriedade de relatórios ao sistema nacional de doação e transplante de cada país e aos correspondentes ministérios da saúde pública, com relação à realização de transplantes com doadores vivos, assim como informações que permitam o rastreamento e acompanhamento desses transplantes.

10. Criar comissões de avaliação para doadores não-aparentados nos hospitais que realizam transplantes.

11. Criar registros nacionais de doação e transplante, que permitam análise adequada dos resultados em curto e longo prazo.

12. Estabelecer critérios para certificação de hospitais onde os procedimentos de transplante são realizados.

13. Registrar e autorizar os programas de transplantes.

14. Estabelecer critérios e protocolos nacionais para a seleção de doadores falecidos.

15. Definir os critérios para certificação do pessoal dedicado a atividades de procura e transplantes.

16. Preparar equipes clínicas de transplante de diversos órgãos, competentes e qualificados, com programas de transplantes que contemplem o pré-transplante, o implante, e as atividades pós-transplante.

17. Treinar o pessoal para as atividades de procura e doação.

18. Estabelecer mecanismos para dar apoio e incentivo aos programas de doador falecido e de procura de órgãos em todos países da Região.

19. Empresas que iniciam a tramitação junto aos ministérios da saúde para aprovação das formulações genéricas de drogas imunossupressoras deverão:

a. Apresentar as referências sobre a origem da droga e seu uso em outros países.

b. Submeter a droga genérica a estudos clínicos de transplante para garantir a segurança e a eficácia terapêutica, com supervisão de terceiros autorizados. Esses estudos devem ser delineados com adequada análise estatística.

c. O fornecimento do medicamento deve ser garantido por um período mínimo de um ano, a fim de evitar o risco de interrupções e intercambialidade dos medicamentos. É comum que o produtor de medicamentos genéricos tenha problemas de produção e / ou de distribuição que limitem o fornecimento adequado dos medicamentos.

20. Difundir o Documento de Aguascalientes em todos os fóruns de transplantes e congressos que se realizarem na América Latina e no Caribe.

21. Enviar este documento a todas as instituições estatais que participam da gestão da saúde na região.

\section{CONCLUSÕES}

Este documento contém o resultado das sessões de trabalho e mesas de discussão do Primeiro Fórum Latino-Americano de Bioética em Transplante. Sua publicação cumpre o objetivo de transmitir seu conteúdo para todos os profissionais de saúde que, dia a dia, envidam seus melhores esforços para atendimento de pacientes que necessitam de um transplante, a todas as sociedades médicas envolvidas em atividades de transplante e às autoridades de saúde de todos os países que formam a América Latina e Caribe.

O documento de Aguascalientes não pretende adotar um caráter dogmático, que censure o exercício dos transplantes; tampouco procurar assumir uma atitude maniqueísta para definir o que é ou não correto.

O documento de Aguascalientes reafirma a sua identidade com os mais altos valores que definem a prática da Medicina; reafirma seu compromisso com a Dignidade, o Respeito pela Vida e de nunca deixar de exercer seu dever de ajudar aqueles que sofrem.

Embora o documento de Aguascalientes admita que cada país e cada centro de transplante têm a prerrogativa de definir suas próprias práticas, ele tem a pretensão de servir como instrumento de expressão em nome dos grupos com atividades de transplantes na América Latina e no Caribe, e seu objetivo é influenciar a realização de transplantes em um ambiente de justiça e equidade.

Possivelmente o maior desafio e, conseqüentemente, a tarefa da qual todos os grupos envolvidos em transplantes terão nos próximos anos, será a implantação e manutenção das medidas necessárias sugeridas neste Documento, com objetivo de otimizar, dentro dos princípios éticos mais rígidos, os resultados em matéria de doação e transplantes que podem ser obtidos a partir do esforço conjunto dos países da região. 


\section{ABSTRACT}

The questionings of a bioethical order, related to organ transplants, posed in the second half of the twentieth century, have motivated intense debates and have constituted an authentic challenge for the scientific, legal, moral and religious ambits during all these years. The question would then be asked as to why - half a century later - the debate regarding the bioethics of transplants is still open? The first Forum on Transplant Bioethics was conceived in the core of the Latin American and Caribbean Transplant Society The Forum originated due to the necessity of creating a space that would permit the analysis of the existing problems in the region. The necessity for reflection was detected, solutions had to be looked for in some cases; in others, we would look to establishing a consensual positioning; in other aspects we would limit ourselves to proposing solutions. The transplant community of Latin America could not remain detached from such a series of problems; they considered it a duty never to be given up. The Document of Aguascalientes reaffirms its identity with the highest values defining the practice of medicine; it reaffirms its commitment with dignity, its respect for life and the never-to-be given up duty of helping those who suffer. Although the Document of Aguascalientes admits that each country and each transplant center have the prerogative of defining their own practices, it does pretend to serve as an instrument of expression on behalf of the groups with transplanting activity in Latin America and the Caribbean, and its aim is to influence the realization of the transplant activities in an atmosphere of justice and equity.

Keywords: Ethics; Transplants; Bioethics.

\section{REFERÊNCIAS}

1. Merrill JP, Murray JE, Harrison JH, Guild WR. Successful homotransplantations of human kidney between identical twins. JAMA 1956; 160:277-82.

2. René Küss, Pierre Bourget. An illustrated history of organ transplantation. Special Commemorative Edition by Laboratoires Sandoz; 1992, p. 18-77.

3. Barnard CN. A human cardiac transplant: an interim report of a successful operation performed at Groote Schuur Hospital, Cape Town. S Afr Med J 1967;41:1271-4.

4. Veatch RM. Transplantation Ethics. Washington, D.C.: Georgetown University Press; p. 46.

5. Ramón Lucas Lucas. Antropología y Problemas Bioéticos. Capítulo VI. En: Muerte encefálica y muerte humana. Madrid: Estudios y Ensayos; 2001, p. 111.

6. Ramón Lucas Lucas. Antropología y Problemas Bioéticos. Capítulo II. El valor del cuerpo humano. Madrid: Estudios y Ensayos; 2001, p. 15.

7. Ruy Pérez-Tamayo. Ética Médica Laica. Fondo de Cultura Económica; El Colegio Nacional México 2002;17-63:250-74.

8. Pius XII. To the delegates of the Italian Association of Cornea Donors and the Italian Union for the Blind (May 14, 1956). In: Acta Apostolicae Sedis. Vatican City 1956; 48:462-5.

9. John Paul II. To the participants at the First International Congress on the Transplant of Organs (June 20, 1991). In: Teachings of Jean Paul II. Vatican City 1991; XIV/1: 1710-12.

10. Pontifical Council for Pastoral Assistance to Health Care Workers. Charter for Health Care Workers. Vatican City 1995;ns 83-91.

11. John Paul II. Enciclical setter "Evangelium Vitae". Vatican City 1995;ns. 15-86.

12. Mollaret P, Goulon M. Le coma dépasse. Revue Neurologiche 1959;101:3-15.

13. Harvard Medical School. A definition of irreversible coma. Report of the Ad Hoc Committee of the Harvard Medical School to Examine the Definition of Brain Death. JAMA 1968;205:337-40.

14. Diagnosis of brain death: statement issued by the honorary secretary of the Conference of Medical Royal Colleges and their Faculties in the United Kingdom on 11 October 1976. Brit Med J 1976;2:1187-8.

15. Guidelines for the determination of death: report of the medical consultants on the diagnosis of death to the President's commission for the study of ethical problems in medicine and biochemical and behavioral research. JAMA 1981; 246:2184-6.

16. Uniform determination of death Act, 12 uniform laws annotated 589 (West 1993 and West suppl 1997).

17. The quality standards subcommittee of the American Academy of Neurology: Practice parameters for determining brain death in aults (summary statement). Neurology 1995;45:1012-4
18. Widjdicks, EFM, Varelas PN, Gronseth GS, Greer DM. Evidence-based guideline update: Determining brain death in adults. Neurology 2010;74:1911-8.

19. Namihira E. Shinto concept concerning the dead human body. Transplant Proc 1990;22:940-1.

20. Sugunasiri SHJ. The Buddhist view concerning the dead body. Transplant Proc 1990;22:947-9.

21. Bulka RP. Jewish perspective on organ transplantation. Transplant Proc. 1990;22:945-6.

22. Al Bar MA. Islamic view on organ transplantation. In Proceedings of the 2nd International Conference of Middle East Society of Organ Transplantation. Kuwait, 11-15 March 1990.

23. SIXTY-THIRD WORLD HEALTH ASSEMBLY. WHA63.22. MAY 2010.

apps.who.int/gb/ebwha/pdf_files/WHA63

24. Declaración de Estambul. Cumbre Internacional sobre turismo de trasplante y tráfico de órganos convocada por la Sociedad de Trasplantes y la Sociedad Internacional de Nefrología en Estambul, Turquía del 30de abril al 2 mayo de 2008. http://www. slanh.org/img/inicio/Declaracion_Estambul.pdf

25. Declaración Universal de los Derechos Humanos, adoptada por la Asamblea General de las Naciones Unidas el 10 de diciembre de 1948, http://www.un.org/Overview/ rights.html

26. Barr, M. L., Belghity J, Villamil F. G. et al: A report of the Vancouver Forum of the Care of the Live Organ Donor: Lung, Liver, Pancreas and Intestines - Data and Medical Guidelines. Transplantation 81:1373-87 2006

27. A report of the Amsterdam Forum on the care of the Live Kidney Donor: data and medical guidelines, Transplantation 79(2S): S53-S66, 2005

28. The Ethics Committee of the Transplantation Society: The consensus of the Amsterdam Forum on the Care of the Live Kidney Donor, Transplantation 78: 491492, 2004

29. Constitución de la Sociedad de Trasplante de América Latina y el Caribe, según aprobada, Canela, Brasil 1999

30. Pan-American Society of Dialysis and Transplantation: Document of Transplant Ethics, Bulletin South Eastern Organ Procurement Foundation, Feb/Mar 1989.

31. Santiago-Delpín, E. A, Guidelines to Assist Authorities in Each Country with

Regards to Transplantation, Transplantation Society Bulletin, 6:9-11, 1997

32. Dossetor JB, Monaco AP, Stiller CR, Guest Editors, First International Congress on Ethics, Justice, and Commerce in Transplantation: A Global View, Transplantation Proceedings, 12(3):891-1056, June 1990. 
33. Sociedad de Trasplantes América Latina y del Caribe. Registro Lationamericano. www.stalyc.net/

34. Kemp, P. La mundialización de la ética, Fontamara: México 2007.

35. Beauchamp, T. y Childress, J. (1999) Principios de Etica Biomédica. Barcelona: Editorial Masson S.A., pp.113,114.

36. Jonas, Hans.(1995) El principio de responsabilidad: ensayo de una ética para la civilización tecnológica. Editorial Herder. México D.F.

37. Cantú, G., Medeiros, M. y col. "En hospitales de México: criterios de asignación de riñón de pacientes fallecidos" Persona y Bioética, 2009;13(32):20-33

38. Cantú, G., Orta Sibu, N., y col. "Patrones de suficiencia y prioridad de la justicia distributiva en atención de los pacientes pediátricos con enfermedad renal crónica terminal en América Latina y el Caribe” Arch.Latin.Nefr.Ped. 2010; 10 (1): 1-9

39. Cantu G. "Justicia Distributiva y trasplante renal" México 2009, en prensa

40. Firmenich B, Fontana R, Barone ME, Fernández M, Maglio I, Tanús E, Tanús R, Exeni R. Turismo de trasplantes: Una mirada desde la bioética. Archivos Latinoamericanos de Nefrología Pediátrica 2008;8(3):205

41. RAWLS, J. "Teoría de la Justicia” segunda edición, 1995. Homedes N. ¿Se puede hablar de políticas de genéricos en América Latina? Revista de salud pública y nutrición de la Universidad Autónoma de Nuevo León 2004;5(1)
42. Declaración de la Asociación Médica Mundial sobre la donación y trasplante de órganos y tejidos-2000- Sección C Valores inc. 7 y Sección H Justicia en el acceso a los órganos y tejidos.

43. Homedes N. ¿Se puede hablar de políticas de genéricos en América Latina? Revista de salud pública y nutrición de la Universidad Autónoma de Nuevo León 2004;5(1)

44. Magos-Guerrero GA, Lorenzana-Jiménez M. Las fases en el desarrollo de nuevos medicamentos. Rev Fac Med UNAM 2009;52(6):260-4

45. Alloway RR, Isaaqcs R, Lake K, Hoyer P. First R, Helderman H, Bunnapradist S, Leichtman AB, Bennett MW, Tejani A, TAkemoto SK. Report of the American Society of Transplantation conference on immunosuppressive drugs and the use of generic immunosuppressants. American Journal of Transplantation 2003;3(10):1211-5

46. Homedes N, Ugalde A. Multisource drug policies in Latin America. Bulletin of WHO 2005;83:64-70

47. Homedes N, López-Linares R, Ugalde A. Health, Nutrition and Population (HNP) Discussion Paper. Generic Drug Policies in Latin America. HNP, The World Bank, March 2005

48. Documento de Consenso en la Utilización de Nuevas Formas Farmacéuticas en Drogas Inmunosupresoras en Pacientes Trasplantados. Ministerio de Salud de la Ciudad Autónoma de Buenos Aires y Sociedad Argentina de Trasplante. 30 de junio de 2010 